\title{
Visual Masking Effect of Familiarity on Facial Expression Processing
}

\author{
J.-Y. Baudouin, S. Sansone and G. Tiberghien
}

\section{(2) OpenEdition}

1 Journals

\section{Electronic version}

URL: http://journals.openedition.org/cpl/152

DOI: $10.4000 / \mathrm{cpl} .152$

ISSN: $1379-6100$

\section{Publisher}

Centre PsyCLÉ

\section{Printed version}

Date of publication: 1 April 2002

\section{Electronic reference}

J.-Y. Baudouin, S. Sansone and G. Tiberghien, « Visual Masking Effect of Familiarity on Facial Expression Processing », Current psychology letters [Online], 2002/1, 7 | 2002, Online since 04 September 2003, connection on 08 September 2020. URL : http://journals.openedition.org/cpl/152 ; DOI : https://doi.org/10.4000/cpl.152

This text was automatically generated on 8 September 2020.

(C) All rights reserved 


\section{Visual Masking Effect of Familiarity on Facial Expression Processing}

J.-Y. Baudouin, S. Sansone and G. Tiberghien 